\title{
Blunted angiogenesis and hypertrophy are associated with increased fatigue resistance and unchanged aerobic capacity in old overloaded mouse muscle
}

\author{
Sam B. Ballak • Tinelies Busé-Pot • Peter J. Harding • \\ Moi H. Yap • Louise Deldicque • Arnold de Haan • \\ Richard T. Jaspers $\cdot$ Hans Degens \\ Received: 2 October 2015 / Accepted: 16 February 2016 / Published online: 12 March 2016 \\ (C) The Author(s) 2016. This article is published with open access at Springerlink.com
}

\begin{abstract}
We hypothesize that the attenuated hypertrophic response in old mouse muscle is (1) partly due to a reduced capillarization and angiogenesis, which is (2) accompanied by a reduced oxidative capacity and fatigue resistance in old control and overloaded muscles, that (3) can be rescued by the antioxidant resveratrol. To investigate this, the hypertrophic response, capillarization, oxidative capacity, and fatigue resistance of $m$. plantaris were compared in 9- and 25-month-old non-treated and 25-month-old resveratrol-treated mice. Overload increased the local capillary-to-fiber ratio less

- Attenuated angiogenesis during overload may contribute to the attenuated hypertrophic response in old age.

- Neither angiogenesis nor hypertrophy is rescued by resveratrol.

- Changes in fatigue resistance with overload and aging were dissociated from changes in SDH activity, but paralleled those in capillarization.
\end{abstract}

S. B. Ballak · P. J. Harding • M. H. Yap · A. de Haan ·

H. Degens $(\bowtie)$

School of Healthcare Science, Manchester Metropolitan

University, Chester Street, John Dalton Building, Manchester M1 5GD, UK

e-mail: h.degens@mmu.ac.uk

S. B. Ballak · T. Busé-Pot · A. de Haan · R. T. Jaspers Laboratory for Myology, Move Research Institute Amsterdam, Faculty of Behavioural and Movement Sciences, Vrije Universiteit Amsterdam, Amsterdam, The Netherlands

\section{Deldicque}

Exercise Physiology Research Group, Department of Kinesiology, FaBeR, KU Leuven, Leuven, Belgium

\section{H. Degens}

Lithuanian Sports University, Kaunas, Lithuania in old $(15 \%)$ than in adult $(59 \%)$ muscle $(P<0.05)$. Although muscles of old mice had a higher succinate dehydrogenase $(\mathrm{SDH})$ activity $(P<0.05)$ and a slower fiber type profile $(P<0.05)$, the isometric fatigue resistance was similar in 9- and 25-month-old mice. In both age groups, the fatigue resistance was increased to the same extent after overload $(P<0.01)$, without a significant change in SDH activity, but an increased capillary density $(P<0.05)$. Attenuated angiogenesis during overload may contribute to the attenuated hypertrophic response in old age. Neither was rescued by resveratrol supplementation. Changes in fatigue resistance with overload and aging were dissociated from changes in SDH activity, but paralleled those in capillarization. This suggests that capillarization plays a more important role in fatigue resistance than oxidative capacity.

Keywords Muscle aging · Hypertrophy · Angiogenesis · Aerobic capacity $\cdot$ Resveratrol

\section{Introduction}

Aging is accompanied by a progressive decline in muscle mass (sarcopenia) and power (Roseberg 1989). These changes not only result in a decreased peak performance, but also in a reduced maximal sustainable power of the muscles as a larger proportion of the available muscle mass has to be recruited for a given task. An age-related reduction in sustainable power can be aggravated by a reduced aerobic capacity to generate ATP. Together, these changes will ultimately limit the ability to perform daily life 
activities and reduce the quality of life (Maden-Wilkinson et al. 2015; Paterson et al. 2007).

During aging, maximal whole-body oxygen consumption per lean mass $\left(\mathrm{VO}_{2 \max }\right)$ decreases (Fleg and Lakatta 1988). In rats, also aerobic power of skeletal muscle is reduced, even when convective oxygen delivery was matched in young and old muscles (Hepple et al. 2003). Such a situation can occur due to a lower oxidative enzyme activity and/or a diminished muscle capillarization, which both have been observed in aged humans (Coggan et al. 1992; Degens 1998; Hepple et al. 1997; Konopka et al. 2014) and rats (Degens et al. 1993b; Skorjanc et al. 2001). Muscle fatigue resistance during intermittent isometric contractions is related to the oxidative capacity of single muscle fibers and motor units (Degens and Veerkamp 1994), and as aerobic metabolism requires an adequate supply of oxygen via the capillaries, it is not surprising that fatigue resistance is also positively related to muscle capillarization (Hudlicka et al. 1977). It has been found that the age-related reduction in oxidative capacity may exceed the loss of capillaries, resulting in a "superfluous" capillary supply in muscles from late-middle aged rats (Hepple and Vogell 2004). In humans, the age-related rate of decline in $\mathrm{VO}_{2 \max }$ accelerates with increasing age (Fleg et al. 2005) and while superfluous capillarization may be a late hallmark of skeletal muscle aging, it is not known whether (1) this also is the case during early stages of sarcopenia, nor (2) how early age-related changes in aerobic capacity and capillarization affect muscle fatigue resistance.

Several studies indicate that the capillary supply to a muscle fiber is positively related to its cross-sectional area in both normal (Ahmed et al. 1997; Wust et al. 2009) and hypertrophied muscle (Degens et al. 1994b). This relationship is tightly regulated, as reflected by the similar time course of fiber hypertrophy and capillary proliferation in a rat model of compensatory hypertrophy (Egginton et al. 2011; Plyley et al. 1998). We therefore hypothesize that a lower muscle capillarization in old age, which would increase the diffusion distance for oxygen and thereby potentially limit muscle oxygenation (Degens et al. 1993b; van der Laarse et al. 2005), contributes to the impaired hypertrophic response observed in muscles from old rodents (Ballak et al. 2015; Degens and Alway 2003) and humans (Kosek et al. 2006; Welle et al. 1996).

Muscle fiber size and oxidative metabolism are inversely related (van der Laarse et al. 1998; van Wessel et al. 2010), which suggests that muscle fiber size and oxidative metabolism are under coordinated control.
Based on this relationship, it is to be expected that the aerobic capacity decreases during muscle (fiber) hypertrophy, and even more so in the older muscles that potentially already have a less dense capillary network to start with. This has, however, not yet been investigated systematically.

If a reduced angiogenic response and impaired mitochondrial function contribute to muscle dysfunction and an attenuated hypertrophic response in old age, then agents that improve angiogenesis and mitochondrial function may normalize muscle function and the hypertrophic response in old age. Resveratrol $\left(3,5,4^{\prime}\right.$ trihydroxystilbene), a polyphenol with antiinflammatory and antioxidant properties (Jackson et al. 2011; Ryan et al. 2010), may be such an agent. Resveratrol has been shown to enhance expression of PGC- $1 \alpha$, improve mitochondrial function in mouse muscle (Lagouge et al. 2006), and to increase expression of vascular endothelial growth factor (VEGF) and its receptor Flk-1 (Fukuda et al. 2006), even in old rodents (Leick et al. 2009; Suzuki et al. 1997).

The objectives of this study were to assess (1) whether the blunted muscle fiber hypertrophy is associated with attenuated angiogenesis, (2) how muscle fatigue resistance changes with age and overload and how this is related to changes in mitochondrial content and/or capillarization, and (3) whether resveratrol improves oxidative capacity and capillarization in 25-month-old mice and rescues the hypertrophic response. To investigate the effects of aging on the hypertrophic response, capillarization, aerobic capacity, and fatigue resistance in m. plantaris, we used 9- and 25-month-old nontreated and 25-month-old resveratrol-treated mice.

\section{Methods}

Ethical approval

All experiments were approved by the local animal use and care committee of the VU University Amsterdam and conformed to the Dutch Research Council's guide for care and use of laboratory animals.

\section{Animals}

At the terminal experiment, adult $(n=11)$ and old $(n=10)$ male C57BL/6J mice (Janvier, France) were 9 and 25 months old, respectively. Mice were kept under 
specific pathogen-free conditions and housed individually at $20-22{ }^{\circ} \mathrm{C}$ at a 12 -h light/dark cycle. Animals were given free access to water and chow (Ssniff ${ }^{\circledR}$ S8189-S095, the same as provided at the supplier). At the age of 7.5 or 23.5 months, the m. gastrocnemius and $m$. soleus of the left leg were denervated to overload the m. plantaris for 6 weeks (Ballak et al. 2015; Degens and Alway 2003). The right leg served as internal control. Another group of old mice (old-res, $n=11$ ) received chow containing $0.4 \%$ resveratrol ( $98.6 \%$ pure, Polygonum cuspidatum extract; 21 st Century Alternative, UK) during the last 7 weeks prior to the terminal experiment, starting 1 week before induction of overload. The old mice were randomly assigned to the old control or old-res group, and all experiments were performed in a random order.

\section{Resveratrol administration}

Since we were only interested to test whether resveratrol could reverse the age-associated blunted hypertrophic response and increase oxidative capacity, we did not include a group of young mice with resveratrol supplementation. The daily intake of resveratrol was approximately $0.4 \mathrm{mg}$ per gram body mass per day, based on a food intake of about $3 \mathrm{~g}$ per day. The food intake was most likely similar in old and old-res mice, since body mass did not change throughout the last 6 weeks prior to the terminal experiment in neither the old nor the old-res mice (Ballak et al. 2015).

Preparation for in situ muscle function

Fifteen minutes prior to surgery, mice received a subcutaneous injection of $0.06 \mathrm{~mL} 1 \%$ Temgesic (Reckitt Benckiser, UK) as an analgesic and were anesthetized with $4 \%$ isoflurane, $0.1 \mathrm{~L} \mathrm{~min}^{-1} \mathrm{O}_{2}$ and $0.2 \mathrm{~L} \mathrm{~min}^{-1}$ air. After nociceptive responses had ceased, the level of anesthesia was maintained with $1.5-2.5 \%$ isoflurane. A humidifier moistened the inhaled air to prevent dehydration due to respiration. The mice were placed on a heated pad to maintain body temperature at $\sim 36.5^{\circ} \mathrm{C}$.

All experiments were performed as described previously (Ballak et al. 2014a; Degens and Alway 2003). The $m$. plantaris was dissected free from surrounding tissue while maintaining its innervation and blood supply. The proximal end of the sciatic nerve was placed over an electrode to stimulate the muscle. The distal tendon of the $m$. plantaris was dissected free and tightened with a Kevlar thread via a small steel bar to a force transducer (de Haan et al. 1989). The femur was fixed by a clamp on the condyle of the femur. During the experiment, the muscle and its surrounding were kept moist at physiological temperature $\left(34-36{ }^{\circ} \mathrm{C}\right)$ with a water-saturated airflow.

\section{Experimental setup and fatigue measurements}

Contractile properties were determined of both the overloaded and contralateral control muscle as described previously (Ballak et al. 2014a). The order of the experiments was randomized. Contractions were elicited by supramaximal electrical stimulation of the sciatic nerve at a constant current $(2 \mathrm{~mA} ; 200-\mu$ s pulse width). Optimal length $\left(\lambda_{\mathrm{o}}\right)$ was defined as the muscle length where maximal tetanic isometric force was generated. To set $\lambda_{\mathrm{o}}$, the length at which the muscle produced maximal twitch force was determined. To fine adjust $\lambda_{\mathrm{o}}$, tetani (stimulation frequency $150 \mathrm{~Hz}, 150 \mathrm{~ms}$ ) were applied once every $2 \mathrm{~min}$. We adjusted the stimulation frequency for the fatigue test so that the force was $\sim 40 \%$ maximal isometric force (test modified for mice from Degens and Alway (2003)) and stimulated the muscle with 330-ms stimulation trains once every $2 \mathrm{~s}$ for $4 \mathrm{~min}$ at this predetermined frequency. Potentiation was calculated as $F_{\max } / F_{1} \cdot 100$, where $F_{\max }$ is the maximal force during the protocol and $F_{1}$ is the tetanic force during the first contraction. The fatigue index (FI) was calculated as the $F_{120} /{ }_{1}$. To correct for potentiation, we also calculated the $F_{120 / \max }$, where $F_{120}$ is the force of the last contraction.

\section{Histology}

The $m$. plantaris was embedded at $\lambda_{\mathrm{o}}$ in a gelatin-tyrode solution and frozen in liquid nitrogen (Ballak et al. 2014a). Within a month after the contraction protocol, serial $10-\mu \mathrm{m}$ cross sections were cut from the mid-belly of the $m$. plantaris in a cryostat at $-20^{\circ} \mathrm{C}$. Sections were mounted on glass slides (Menzel-Gläser, Superfrost ${ }^{\circledR}$ Plus, GER), air-dried and stored at $-80^{\circ} \mathrm{C}$ until further use. All chemicals were obtained from Sigma-Aldrich (The Netherlands) unless stated otherwise.

One section was stained for succinate dehydrogenase (SDH), a marker of oxidative capacity, as described previously (van der Laarse et al. 1989). SDH activity was calculated as the absorbance at $660 \mathrm{~nm} \mathrm{\mu m}^{-1} \mathrm{sec}-$ tion thickness per second of staining time 
$\left(\Delta \mathrm{A} 660 \mu \mathrm{m}^{-1} \mathrm{~s}^{-1}\right)$. The integrated SDH was calculated as the product of muscle fiber CSA and SDH activity.

Capillaries were stained with biotinylated lectin (Griffonia simplicifolia). Sections were fixed in icecold acetone for $15 \mathrm{~min}$ and washed with HEPES buffer for $5 \mathrm{~min}$. After blocking with $0.1 \%$ bovine serum albumin (BSA) in HEPES for $60 \mathrm{~min}$ and being washed with HEPES, the sections were incubated with hydrogen peroxide for $30 \mathrm{~min}$. After washing in HEPES, the sections were incubated with lectin for an hour (Vector Laboratories, UK), washed three times with HEPES, and incubated with VIB substrate (Vector Laboratories, UK). Then, the sections were washed with $\mathrm{dH}_{2} \mathrm{O}$ and enclosed with glycerin-gelatin.

Serial sections were immunohistochemically stained for type I, IIA, IIX, and IIB MHC to distinguish muscle fiber types (Ballak et al. 2014a). Thereto, monoclonal antibodies specific against types I, IIA, IIX, and IIB were used; BAD5, SC-71, 6H1, and BF-F3 (Developmental Studies Hybridoma Bank, USA), respectively. In short, sections were fixated with acetone for $10 \mathrm{~min}$ at $4{ }^{\circ} \mathrm{C}$ and washed three times in phosphate-buffered saline (PBS) plus Tween (PBST). After blocking with $10 \%$ normal swine serum for $30 \mathrm{~min}$, sections were incubated with the primary antibody. Subsequently, sections were washed in PBST three times and incubated in the dark with secondary antibody (Alexa 488 antimouse, Molecular Probes) for $30 \mathrm{~min}$. After washing with PBST, incubating with wheat germ agglutinin (WGA) for $20 \mathrm{~min}$, washing with PBST and subsequently washing once more with PBS - all in the dark-sections were enclosed in Vectashield ${ }^{\circledR}$-Hard Set Mounting Medium with DAPI (Vector Laboratories, USA).

\section{Morphometric analysis}

The morphometric analysis of the muscle samples was done single-blinded, where the experimenter did not know the origin of the analyzed section. The method of capillary domains has been used to analyze muscle capillarization, fiber type composition, and the relationship between capillarization and SDH activity (Degens et al. 1992; Hoofd et al. 1985; Wust et al. 2009). Recently, a semiautomatic domain method has been developed and validated (Ballak et al. 2016), based on the calculations in AnaTis (BaLoH Software, www.baloh. $\mathrm{nl}$ ). The capillary domain is a good representation of the oxygen supply area of a capillary (Al-Shammari et al.
2014). Briefly, coordinates of fiber outlines and capillaries were traced and stored. Capillary domains were constructed by applying Voronoi tessellation, which creates equidistant boundaries around each capillary. The fiber cross-sectional area (FCSA) and capillary domain sizes were calculated. Besides the usual indices of capillary density (CD; cap $\mathrm{mm}^{-2}$ ) and capillary-tofiber ratio $(\mathrm{C} / \mathrm{F})$, the method allows the calculation of the capillary supply to individual fibers, even those lacking direct capillary contacts. The capillary supply to a fiber was expressed as the local capillary-to-fiber ratio (LCFR; sum of the fractions of the capillary domains overlapping a given fiber) and the capillary fiber density (CFD; LCFR divided by the FCSA of a particular fiber). The logarithmic standard deviation of the radius of the capillary domains provides an index of the heterogeneity of capillary spacing $\left(\log _{\mathrm{rSD}}\right)$. This analysis was performed for the glycolytic and oxidative regions of the muscle separately.

Western blot

Frozen muscle tissue $(\sim 5-10 \mathrm{mg} ; 1: 40, w / v)$ was homogenized as described before (Ballak et al. 2015). Homogenates were centrifuged at $10,000 \mathrm{~g}$ for $10 \mathrm{~min}$ at $4{ }^{\circ} \mathrm{C}$. The supernatant was immediately stored at $-80{ }^{\circ} \mathrm{C}$ and the protein concentration was measured using the DC protein assay kid (Bio-Rad Laboratories, Nazareth, Belgium). Forty micrograms of protein was separated by SDS-PAGE (10-12\% gels) and transferred to PVDF membranes. Membranes were blocked with $5 \%$ nonfat milk for $1 \mathrm{~h}$ and then incubated overnight $\left(4{ }^{\circ} \mathrm{C}\right)$ with the following antibodies: SDH $(1: 10,000$, Santa Cruz, UK), cytochrome c oxidase subunit 4 (COX-4) (1:1000, Abcam, Cambridge, UK), Flk-1 (1:500, Santa Cruz, UK), and eukaryotic elongation factor 2 (eEF2) (1:1000, Cell Signaling Technology, Leiden, The Netherlands). Horseradish peroxidaseconjugated anti-mouse $(1: 10,000)$ or anti-rabbit (1:5000) secondary antibodies (Sigma-Aldrich, Bornem, Belgium) were used for chemiluminescent detection. Membranes were scanned and quantified with Genetools and Genesnap software (Syngene, Cambridge, UK), respectively. Preliminary experiments showed that eEF2 content was stable across the different treatments and conditions, and results are presented as the ratio protein of interest/eEF2. 
Statistics

A repeated-measures ANOVA, with as within-factor overload and between-factor age, was used to test for effects of overload and age on fatigue resistance. To test for the effects of (1) age and overload, or (2) resveratrol and overload on mean FCSA, mean (integrated) SDH, COX4 and FLK-1 expression, CD, C/F, $\log _{\mathrm{rSD}}$ data, we used a univariate three-way ANOVA (IBM SPSS version 20) with the following factors: (1) age, muscle region (where appropriate) and overload, or (2) resveratrol, muscle region (where appropriate) and overload. In cases of fiber typespecific parameters (integrated) SDH, LCFR and CFD, the independent factor "muscle fiber type" was added to determine differences between fiber types. Effects were considered significant at $P<0.05$. Data are expressed as means \pm standard error of the mean (SEM).

\section{Results}

Effects of age, overload and resveratrol on fatigue resistance and potentiation

Table 1 shows that overload resulted in an increase in muscle mass and maximal tetanic force in both adult and old mice, irrespective of supplementation with resveratrol $(P<0.05)$ (Ballak et al. 2014a).

Figure 1 shows tetanic force normalized for the tetanic force of the first contraction during the fatigue test. The potentiation during the fatigue protocol was similar in adult and old muscles. Overload did not significantly alter potentiation in adult or old muscle. Resveratrol reduced potentiation in overloaded muscle only (resveratrol $\times$ overload interaction, $P<0.05$; Table 1 ).

After potentiation, the force of the adult and old control muscles dropped rapidly to $\sim 50 \%$ of the initial value at the end of the test. Overload did result in an increased fatigue resistance; the forces at the end of the protocol were $65-70 \%$ of the initial values (Table 1; Fig. $1 ; P<0.05)$. Resveratrol did not significantly affect fatigue resistance.

Effects of age, overload and resveratrol on muscle fiber size and muscle fiber type composition

In all groups, the FCSA of type IIB and IIX fibers was larger than that of type IIA fibers, and in the oxidative region of the $m$. plantaris, the FCSA of all fibers, except
IIB fibers, was larger than those in the glycolytic part (Table 2; $P<0.01$ ).

Age and overload The FCSA was lower in old than adult muscle, but increased by overload in both groups (Fig. 2; $P<0.05)$. More specifically, overload increased the FCSA of type IIA, IIAX, and IIX fibers $(P<0.01)$, but more so in adult than old muscle (age $\times$ overload, $P<0.01$; Table 2), indicating an attenuated hypertrophic response in old age.

Age and resveratrol Resveratrol increased the pooled FCSA in both old control and old overloaded muscles (Fig. 2; $P<0.05$ ) and specifically so in type IIAX, IIX, IIXB and IIB fibers (Table 2; $P<0.05$ ). There was no significant resveratrol $\times$ overload interaction, indicating that resveratrol did not rescue the attenuated hypertrophic response.

Age and overload Age did not significantly affect the area percentage of each fiber type. In adult, but not in old mice, overload did result in an increased proportion of the muscle occupied by type IIA, IIAX, IIX and IIXB fibers at the expense of type IIB fibers (age $\times$ overload, $P<0.05$; Table 2).

Age and resveratrol Resveratrol supplementation resulted in a $10 \%$ larger areal percentage of IIB fibers $(P<0.05)$, which was obliterated after overload (resveratrol $\times$ overload, $P<0.05$ ).

Effects of age, overload and resveratrol on SDH activity

Mass-specific SDH activity is reflected by the SDH$O D$ Type IIB fibers had the lowest and type IIA the highest SDH activity, with that of type IIX fibers in between (Fig. 3a, b; $P<0.01$ ). Furthermore, SDH activity in IIB fibers in the glycolytic region was $10 \%$ lower than that in the oxidative region of the muscle irrespective of age and resveratrol supplementation (Fig. 3a, b; $P<0.05$ ).

Age and overload The SDH activity was $20 \%$ higher in old than in adult muscle (Fig. 3c; $P<0.05$ ), suggesting a higher oxidative capacity in aged muscle. Overload did not significantly affect the $\mathrm{SDH}$ activity $(P>0.05)$.

Age and resveratrol Resveratrol increased only the SDH activity of type IIB fibers in the glycolytic region by $28 \%$ (Fig. $3 b ; P<0.05$ ). 
Table 1 Muscle mass, maximal isometric force, potentiation and fatigue resistance in control and overloaded $m$. plantaris of adult, old and old-res mice

\begin{tabular}{|c|c|c|c|c|c|c|}
\hline & \multicolumn{2}{|c|}{ Adult mice $(n=7)$} & \multicolumn{2}{|c|}{ Old mice $(n=10)$} & \multicolumn{2}{|c|}{ Old-res mice $(n=10)$} \\
\hline & Con vs. Ovl & & Con vs. Ovl & & Con vs. Ovl & \\
\hline Muscle mass (mg) & $24.2 \pm 0.7$ & $32.1 \pm 1.2^{*}$ & $22.4 \pm 0.7^{* *}$ & $28.1 \pm 1.1^{*}$ & $23.8 \pm 0.8$ & $29.8 \pm 0.9^{*}$ \\
\hline Max force $(\mathrm{mN})$ & $497 \pm 34$ & $663 \pm 50^{*}$ & $470 \pm 22$ & $579 \pm 36^{*}$ & $529 \pm 30$ & $557 \pm 39^{*}$ \\
\hline Potentiation (\%) & $31.5 \pm 5.6$ & $29.2 \pm 6.8$ & $47.8 \pm 6.8$ & $35.4 \pm 3.9$ & $51.3 \pm 4.3$ & $19.3 \pm 6.1^{* * * * *}$ \\
\hline $\mathrm{FI}_{120 / 1}$ & $49.9 \pm 1.0$ & $66.2 \pm 4.9^{*}$ & $51.6 \pm 8.2$ & $70.0 \pm 5.6^{*}$ & $58.0 \pm 3.8$ & $64.3 \pm 5.2^{*}$ \\
\hline $\mathrm{FI}_{120 / \max }$ & $38.3 \pm 1.4$ & $51.8 \pm 4.4^{*}$ & $34.2 \pm 5.1$ & $52.5 \pm 5.5^{*}$ & $38.4 \pm 2.5$ & $54.3 \pm 4.6^{*}$ \\
\hline
\end{tabular}

Muscle mass was reported previously (Ballak et al. 2015). Max force: the maximal achieved force during the fatigue protocol. $\mathrm{FI}_{120 / 1}$ : fatigue index for $\sim 40 \%$ of tetanic force (not reported here), dividing the force of the 120 th contraction by the first. $\mathrm{FI}_{120 / \text { max }}$ : fatigue index for $\sim 40 \%$ of tetanic force (not reported here), dividing the force of the 120th contraction by the maximal achieved force during the fatigue protocol. Values are mean \pm SEM

*Different from control condition at $P<0.05, * *$ different from adult at $P<0.05, * * *$ overload $\times$ resveratrol interaction at $P<0.05$

Total SDH activity is reflected by the integrated SDH activity Type IIB fibers had a $31 \%$ lower integrated SDH activity than IIX fibers $(P<0.01)$, while the integrated SDH activity of IIA fibers was comparable to that of IIX fibers $(P>0.05)$. Type IIX fibers in the glycolytic region had a $14 \%$ lower integrated SDH activity than those in the oxidative region of the muscle $(P<0.01)$.

Age and overload The integrated SDH activity of type IIA fibers was $21 \%$ lower in adult than old muscles (Fig. 3d, e; $P<0.01$ ). Overload increased the integrated SDH irrespective of age, resveratrol supplementation, or fiber type $(P<0.01)$. The increase in integrated SDH activity, but not in SDH activity, suggests that mitochondrial biogenesis and fiber hypertrophy during overload were proportional.

Age and resveratrol Resveratrol did not significantly affect the integrated SDH activity (Fig. 3d, e).

Mitochondrial protein expression In contrast to the elevated SDH activity, western blot analyses revealed that SDH protein expression was not significantly affected by age (Fig. 4a). This suggests that the specific activity of the SDH complex was increased by age. COX-4
Fig. 1 Effects of age, overload and resveratrol on in situ plantaris muscle fatigue resistance. Plantaris force $(\%$ of the force during the first contraction) is expressed as contraction number percentage of first contraction in the $m$. plantaris for adult (circle), old (triangle) and old-res (square) mice in both control (black) and overloaded (white) conditions

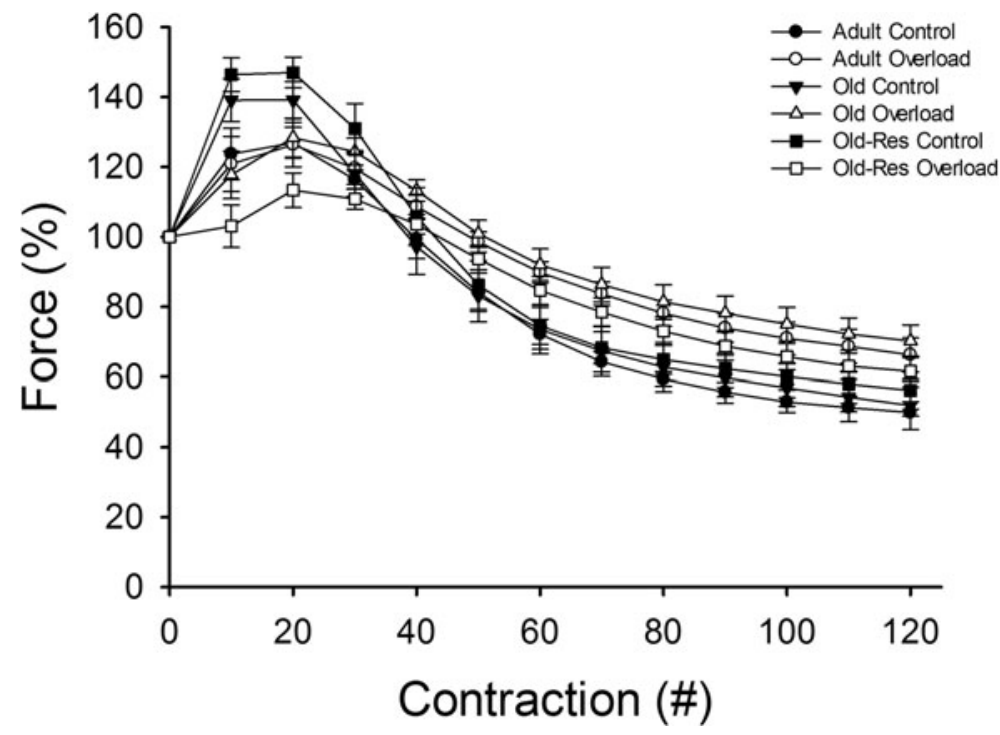


Table 2 Effects of age, overload and resveratrol supplementation on muscle fiber type area and fiber cross-sectional area

\begin{tabular}{|c|c|c|c|c|c|c|c|c|c|}
\hline & & \multicolumn{4}{|l|}{$\operatorname{FCSA}\left(\mu \mathrm{m}^{2}\right)$} & \multicolumn{4}{|c|}{ Fiber type area \% } \\
\hline & & ConG & $\mathrm{ConO}$ & OvlG & OvlO & ConG & $\mathrm{ConO}$ & OvlG & OvlO \\
\hline \multirow[t]{5}{*}{ Adult } & IIA & $458 \pm 59$ & $642 \pm 37^{\mathrm{e}}$ & $894 \pm 123^{b}$ & $1046 \pm 42^{\mathrm{b}, \mathrm{e}}$ & $7.1 \pm 3.4$ & $21.0 \pm 1.4^{\mathrm{e}}$ & $9.3 \pm 3.0$ & $30.9 \pm 3.3^{\mathrm{e}}$ \\
\hline & IIAX & $503 \pm 64$ & $839 \pm 83^{\mathrm{e}}$ & $1066 \pm 188^{b}$ & $1260 \pm 49^{\mathrm{b}, \mathrm{e}}$ & $3.0 \pm 3.2$ & $5.6 \pm 2.0$ & $11.3 \pm 1.7^{\mathrm{b}}$ & $17.1 \pm 1.9^{\mathrm{b}}$ \\
\hline & IIX & $1023 \pm 123$ & $1284 \pm 65^{\mathrm{e}}$ & $1616 \pm 196^{\mathrm{b}}$ & $1883 \pm 125^{\mathrm{b}, \mathrm{e}}$ & $19.0 \pm 7.4$ & $29.8 \pm 2.7$ & $38.4 \pm 5.8^{\mathrm{b}}$ & $36.4 \pm 4.0$ \\
\hline & IIXB & $1234 \pm 400$ & $1284 \pm 334$ & $1770 \pm 172^{b}$ & $1875 \pm 72^{\mathrm{b}, \mathrm{e}}$ & $0.9 \pm 1.2$ & $2.3 \pm 1.5$ & $9.4 \pm 3.9^{\mathrm{b}}$ & $2.6 \pm 0.9$ \\
\hline & IIB & $1790 \pm 185$ & $1785 \pm 71$ & $2361 \pm 221^{\mathrm{b}}$ & $1868 \pm 173^{\mathrm{b}}$ & $70.0 \pm 15.2$ & $41.3 \pm 2.7^{\mathrm{e}}$ & $31.7 \pm 9.2^{\mathrm{b}}$ & $9.7 \pm 3.5^{\mathrm{e}, \mathrm{b}}$ \\
\hline \multirow[t]{5}{*}{ Old } & IIA & $504 \pm 49$ & $840 \pm 70^{\mathrm{e}}$ & $654 \pm 98^{\mathrm{a}}$ & $918 \pm 146^{\mathrm{e}}$ & $11.2 \pm 2.2$ & $34.1 \pm 5.6$ & $7.0 \pm 1.7$ & $34.5 \pm 6.5$ \\
\hline & IIAX & $535 \pm 86$ & $1064 \pm 193^{\mathrm{e}}$ & $592 \pm 83^{\mathrm{a}}$ & $985 \pm 106^{\mathrm{e}}$ & $1.8 \pm 0.1$ & $2.9 \pm 1.2^{\mathrm{a}}$ & $2.7 \pm 1.2^{\mathrm{a}}$ & $7.5 \pm 2.8^{\mathrm{b}, \mathrm{a}}$ \\
\hline & IIX & $864 \pm 80^{\mathrm{a}}$ & $1408 \pm 179^{\mathrm{e}}$ & $1086 \pm 102^{\mathrm{a}}$ & $1355 \pm 206^{\mathrm{e}, \mathrm{a}}$ & $25.8 \pm 1.0$ & $36.0 \pm 3.2$ & $27.2 \pm 3.7^{\mathrm{b}}$ & $34.1 \pm 3.4$ \\
\hline & IIXB & $843 \pm 174^{\mathrm{a}}$ & $1398 \pm 379^{\mathrm{e}}$ & $1168 \pm 186^{\mathrm{b}, \mathrm{a}}$ & $1543 \pm 107^{\mathrm{b}, \mathrm{e}}$ & $1.6 \pm 0.5$ & $2.5 \pm 0.8$ & $3.0 \pm 1.0^{\mathrm{b}, \mathrm{a}}$ & $4.6 \pm 2.0$ \\
\hline & IIB & $1446 \pm 201^{\mathrm{a}}$ & $1929 \pm 263$ & $1726 \pm 130^{\mathrm{a}}$ & $1676 \pm 144$ & $60.4 \pm 1.7^{\mathrm{a}}$ & $24.6 \pm 6.2$ & $60.1 \pm 6.0^{\mathrm{b}, \mathrm{a}}$ & $20.2 \pm 5.8$ \\
\hline \multirow[t]{5}{*}{ Resveratrol } & IIA & $509 \pm 62$ & $757 \pm 86^{\mathrm{e}}$ & $873 \pm 126^{\mathrm{b}, \mathrm{c}}$ & $986 \pm 117^{\mathrm{e}, \mathrm{b}}$ & $4.3 \pm 2.4^{\mathrm{c}}$ & $24.1 \pm 3.2^{\mathrm{c}, \mathrm{e}}$ & $6.0 \pm 1.6$ & $36.8 \pm 3.6^{\mathrm{e}}$ \\
\hline & IIAX & $772 \pm 92^{\mathrm{c}}$ & $831 \pm 129^{\mathrm{e}}$ & $986 \pm 132^{\mathrm{c}}$ & $1116 \pm 202^{\mathrm{e}}$ & $1.6 \pm 0.7$ & $3.5 \pm 0.9$ & $5.7 \pm 1.4^{\mathrm{b}}$ & $9.9 \pm 3.0^{\mathrm{b}}$ \\
\hline & IIX & $1270 \pm 112^{\mathrm{c}}$ & $1557 \pm 153^{\mathrm{e}}$ & $1608 \pm 80^{\mathrm{b}, \mathrm{c}}$ & $1686 \pm 134^{\mathrm{e}}$ & $19.8 \pm 2.7$ & $34.1 \pm 4.6$ & $34.1 \pm 5.0$ & $31.9 \pm 1.8$ \\
\hline & IIXB & $1547 \pm 249^{c}$ & $1498 \pm 288$ & $1469 \pm 84^{\mathrm{c}}$ & $1227 \pm 253$ & $2.9 \pm 1.1^{\mathrm{c}}$ & $3.5 \pm 1.7$ & $10.8 \pm 4.9^{\mathrm{b}, \mathrm{c}}$ & $3.6 \pm 1.9$ \\
\hline & IIB & $1776 \pm 137^{\mathrm{c}}$ & $1970 \pm 152$ & $2115 \pm 188^{\mathrm{c}}$ & $1866 \pm 183$ & $71.4 \pm 5.4^{\mathrm{c}}$ & $34.9 \pm 6.0^{\mathrm{e}}$ & $43.5 \pm 11.5$ & $16.4 \pm 4.5^{\mathrm{e}}$ \\
\hline
\end{tabular}

Glycolytic (ConG) and oxidative (ConO) regions of the $M$. plantaris in control condition were separated for analysis of FCSA and fiber type area $\%$. The same was done for glycolytic $(\mathrm{OvlG})$ and oxidative $(\mathrm{OvlO})$ regions in overloaded condition. Values are mean \pm SEM. Note that in muscle cross sections, low numbers of hybrid fibers were found, particularly type IIXB mounting up to about only $2-3 \%$ of all fibers

${ }^{a}$ Significantly different compared to adult muscle $(P<0.05)$

${ }^{\mathrm{b}}$ Significantly different compared to control muscle $(P<0.05)$

${ }^{\mathrm{c}}$ Significantly different from old muscle $(P<0.05)$

${ }^{\mathrm{d}}$ Significantly different from glycolytic region

protein expression did decrease with age (Fig. 4a; $P<0.05$ ). Despite the lower COX-4 expression, the $\mathrm{SDH} / \mathrm{COX}-4$ ratio was not significantly altered by age (Fig. 4b; $P>0.05$ ).

\section{Overall muscle capillarization}

Both $\mathrm{CD}$ and $\mathrm{C} / \mathrm{F}$ were significantly higher ( $\sim 35$ and $\sim 18 \%$, respectively) in the oxidative than the glycolytic region of the muscle $\left(P<0.01\right.$; Fig. 5a, b). $\log _{\text {rSD }}$ was $11 \%$ higher in the glycolytic than in the oxidative region of the $m$. plantaris muscle $(P<0.01)$, indicating a larger heterogeneity in capillary spacing in the glycolytic than in the oxidative region of the muscle.

Age and overload $\mathrm{CD}$ was not significantly affected by age, but increased $\sim 20 \%$ by overload $(P<0.01)$. C/F was unaffected by age, but increased by overload $(P<0.01$; Fig. $5 b)$ and more so in adult (44\%) than old (16\%)

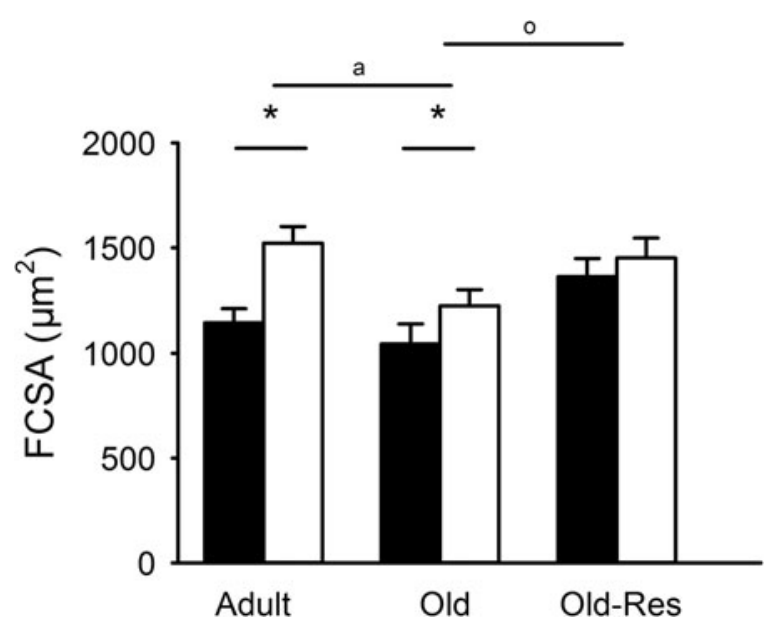

Fig. 2 Effects of age, overload and resveratrol on $m$. plantaris FCSA. FCSA was smaller in old compared to adult muscle ( $\left.{ }^{\mathrm{a}} P<0.05\right)$, bigger in old-res than old muscle $\left({ }^{\mathrm{o}} \mathrm{P}<0.05\right)$ and increased after overload in adult and old $(* P<0.01)$, but not in old-res muscle. Values are represented as percentage of the adult control muscle; mean \pm SEM 

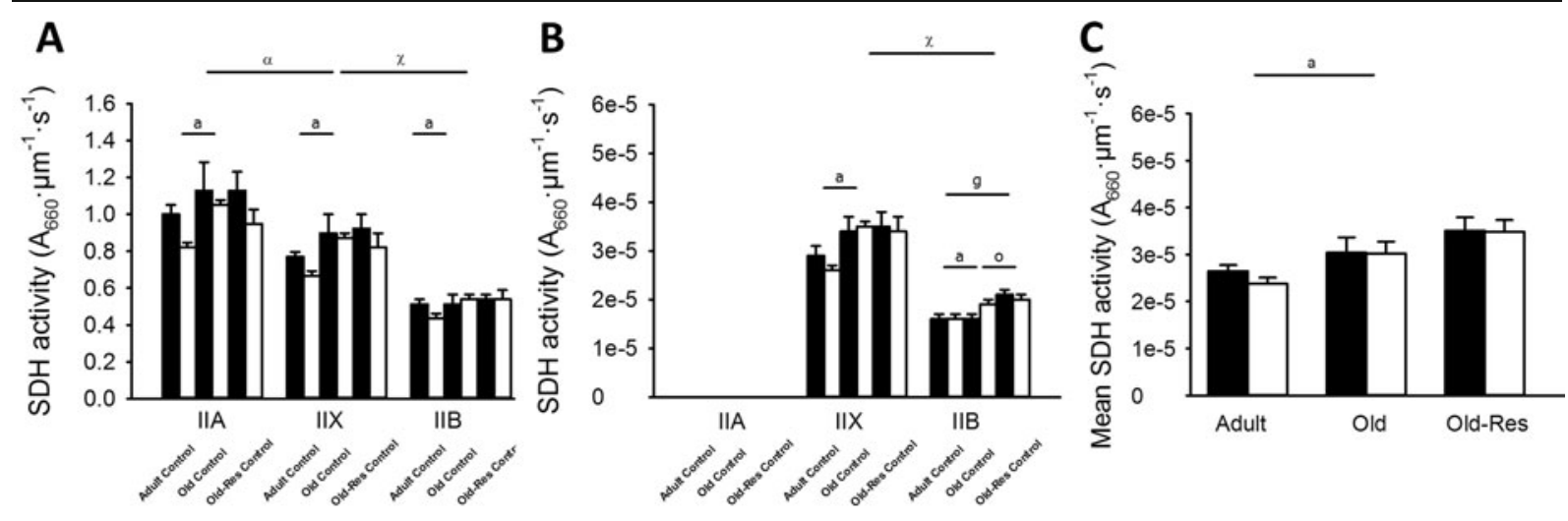

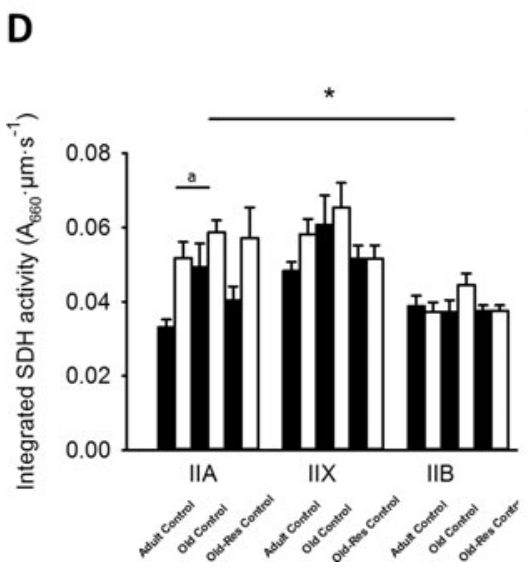

E
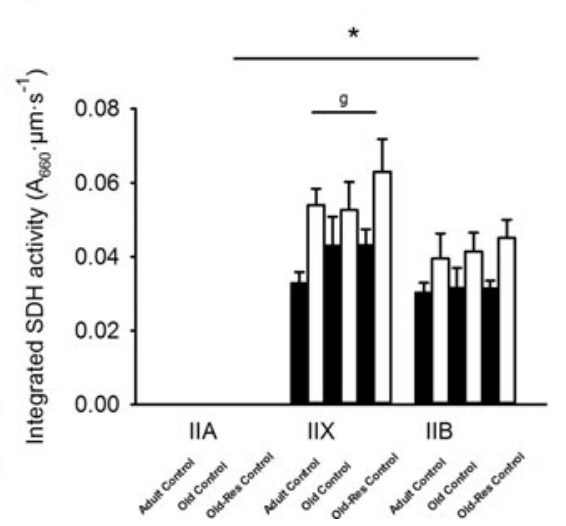

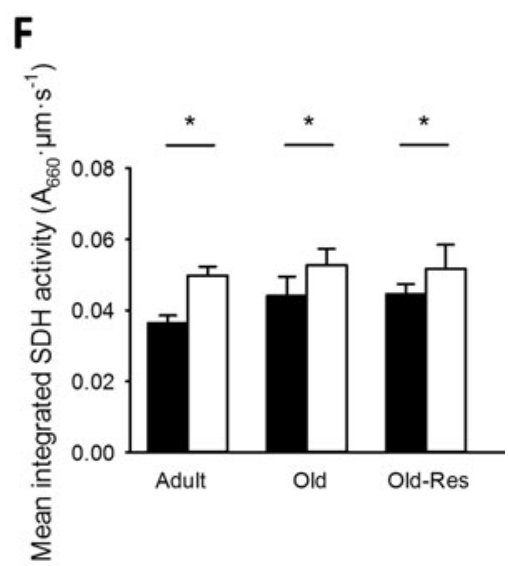

Fig. 3 SDH activity and integrated SDH activity per fiber type for adult, old and old-res muscle. SDH activity for adult, old and oldres muscle in control and overloaded condition for type A, X, and $\mathrm{B}$ fibers in the oxidative (a) and glycolytic (b) region of the muscle. c Mean SDH for adult, old and old-res mice in both control (black) and overloaded (white) conditions. SDH activity in old muscle was higher than in adult muscle ( ${ }^{\mathrm{a}} P<0.05$ ). SDH activity was higher in old compared to adult muscle for all three fiber types $(P<0.05)$. Furthermore, the SDH activity in IIB of the glycolytic region of the muscle was lower than of type IIB fibers in the oxidative region $\left({ }^{g} P<0.05\right)$. Resveratrol did only increase SDH activity in type IIB fibers of the glycolytic region of the muscle $(P<0.05)$. SDH activity was lower in type IIB compared

muscle (age $\times$ overload, $P<0.05$ ). $\log _{\mathrm{rSD}}$ was not significantly affected by age (Fig. 5), but overload reduced $\log _{\text {rSD }}$ by $9 \%$, indicating a more homogeneous distribution of the capillaries in the hypertrophied muscles $(P<0.01)$. Figure 6 illustrates the analysis of capillary data.

Age and resveratrol In resveratrol-treated muscle, overload only increased CD in the oxidative region by $18 \%$ (resveratrol $\times$ overload, $P<0.05$; Fig. 5a). Resveratrol, however, did not significantly affect $\mathrm{C} / \mathrm{F}$ or $\log _{\mathrm{rSD}}$ $(P>0.05)$. to IIX fibers $\left({ }^{\times} P<0.01\right)$ and lower in IIX compared to IIA fibers $\left({ }^{\alpha} P<0.01\right)$. Integrated SDH activity for adult, old, and old-res muscle in control and overloaded condition for type A, X, and B fibers in the oxidative region (d) and glycolytic region (e) of the muscle. f Mean integrated SDH for adult, old, and old-res mice in both control (black) and overloaded (white) conditions. Integrated SDH activity increased after overload for all three fiber types $(P<0.01)$. Old muscle showed a higher integrated SDH activity in type IIA fibers, compared to adult $(P<0.01)$. Type IIX fibers had a lower integrated SDH activity in the glycolytic region, compared to the oxidative region $(P<0.01)$. Data shown are mean \pm SEM

\section{Muscle fiber-specific capillarization}

For all groups, LCFR was higher in the oxidative than in the glycolytic region (Fig. 7; $P<0.01$ ).

Age and overload LCFR of all muscle fiber types was not significantly affected by age. However, overload increased LCFR in fibers of all types (Fig. 7a, b; $P<0.05$ ), except that of type IIB fibers in the oxidative region (Fig. 7a). The overload-induced increase in LCFR was $57 \%$ in 
adult versus $14 \%$ in old muscle (age $\times$ overload, $P<0.05$ ), indicating attenuated angiogenesis in old overloaded muscles. In most cases, the CFD was not significantly affected by age or overload (Fig. 7e, f), but there was a significant age $\times$ overload interaction $(P<0.05)$ for type IIAX and IIX fibers, reflected by a decrease in CFD in old, but not adult, overloaded plantaris muscle.

Age and resveratrol Resveratrol did not significantly affect LCFR (Fig. 7c, d). In both old and old-res, CFD of type IIX and IIB fibers was lower in the glycolytic than the oxidative region of the muscle (Fig. $7 \mathrm{~g}-\mathrm{h}$; age $\times$ overload interaction, $P<0.05$ ). Resveratrol decreased CFD of IIAX fibers in the glycolytic region of the muscle by $26 \%$ (resveratrol $\times$ region interaction, $P<0.05)$.

\section{VEGF and Flk-1 protein expression}

Flk-1 protein expression, a receptor for VEGF, was $31 \%$ lower in the $m$. plantaris from old than young-adult mice (Fig. 4c; $P<0.05$ ), irrespective of overload or resveratrol supplementation.
Overload affects inverse relationship between SDH and FCSA

Figure 8 shows that in the muscles from both adult and old mice, there is an inverse relationship between SDH activity and FCSA $\left(R^{2}=0.74\right.$ and $R^{2}=0.67$, respectively, both $P<0.01)$. Overload induced a rightward shift of the fitted hyperbola.

The LCFR of adult and old muscle correlated strongly with the FCSA $\left(R^{2}=0.52, P<0.05\right)$, but not with the SDH activity $\left(R^{2}=0.07, P>0.05\right)$, suggesting that the capillary supply to a fiber is more determined by fiber size than fiber oxidative capacity.

\section{Discussion}

Here, we investigated whether sarcopenia and the blunted hypertrophic response in old mouse muscle (1) are partly due to a reduced capillarization and angiogenesis, that are (2) accompanied with a reduced oxidative capacity and fatigue resistance in old control and overloaded muscles, and that (3) can be rescued by the anti-inflammatory antioxidant resveratrol. The main observations were that

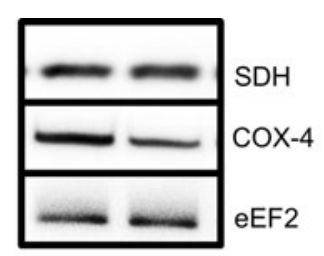

Adult Old

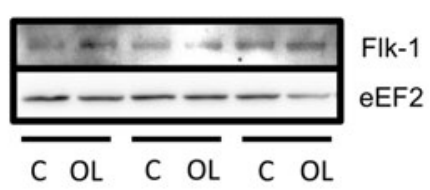

Adult Old Old-Res
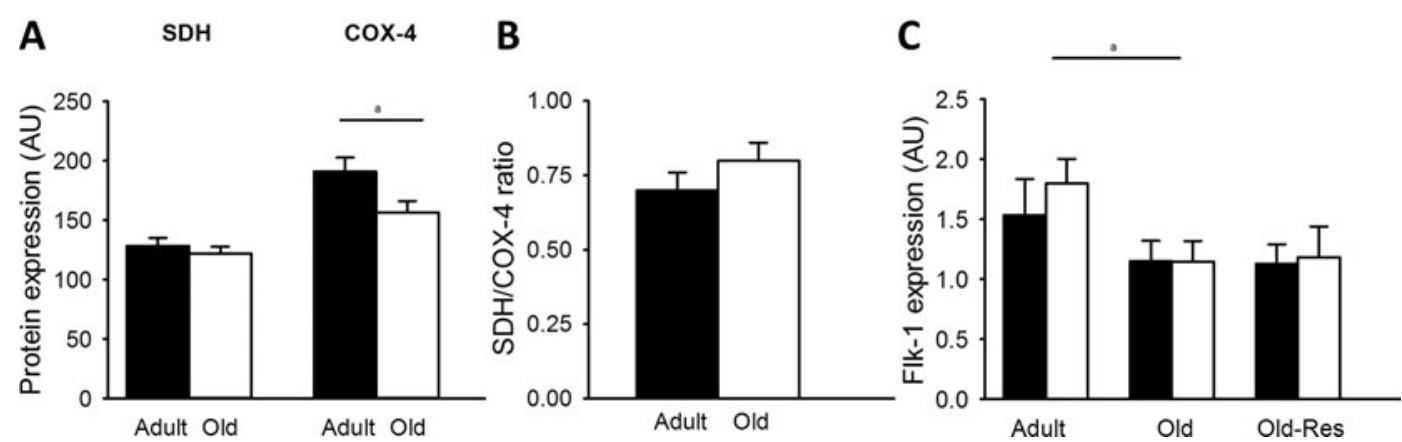

Fig. 4 Flk-1, SDH, and COX-4 protein expression in adult, old and old-res muscle. a SDH protein expression was similar in adult and old muscle, while COX-4 protein expression was decreased in old muscle $\left({ }^{\mathrm{a}} P<0.05\right)$. The SDH/COX-4 ratio (b) was not significantly different in aged muscle. c Flk-1 protein expression

in $m$. plantaris, an important receptor for VEGF, was decreased in old compared to adult muscle $\left({ }^{\mathrm{a}} P<0.05\right)$, but not affected by overload or resveratrol. The results are presented as the ratio protein of interest/loading control (eEF2). Values are mean $\pm \mathrm{SEM}$ 

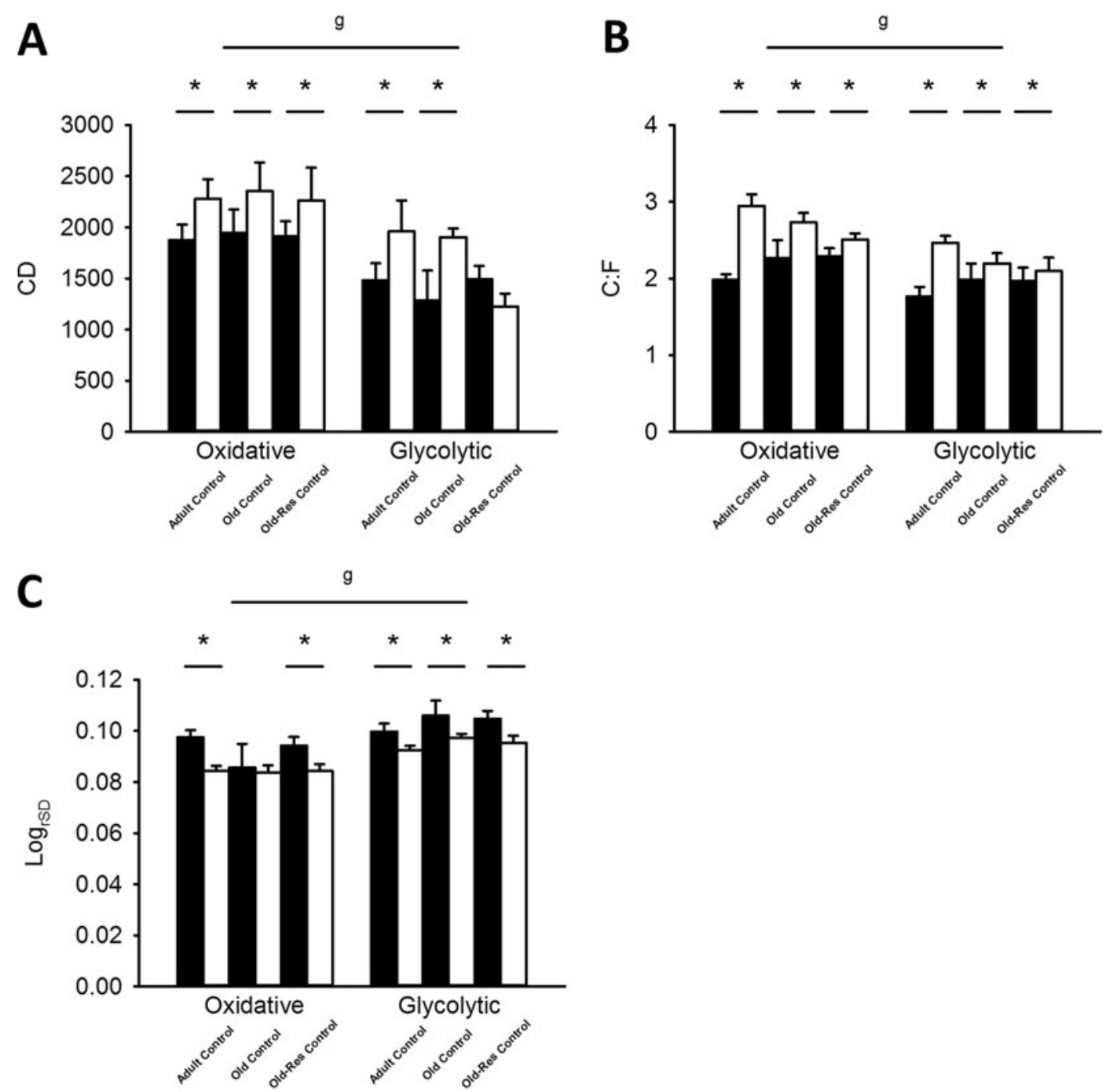

Fig. 5 Effects of age, overload, and resveratrol on $\mathrm{CD}, \mathrm{C} / \mathrm{F}$, and $\log _{\text {rSD }}$ a $C D$ was unaffected by age, however increased by overload $(P<0.01)$. Resveratrol blunted the overload-induced increase in $\mathrm{CD}$, but only in the glycolytic region of the muscle (resveratrol $\times$ overload, $P<0.05$ ). b $\mathrm{C} / \mathrm{F}$ was increased by overload $(P<0.01)$, but unaffected by age or resveratrol. Both $C D$ and $\mathrm{C} / \mathrm{F}$ were higher in the oxidative region of the $m$. plantaris compared to the glycolytic region. $\mathbf{c} \log _{\text {rSD }}$ for adult, old and

both overload-induced hypertrophy and angiogenesis of the $m$. plantaris were attenuated in old mice. Despite the diminished angiogenic response and the unaltered aerobic capacity, the fatigue resistance was increased to a similar extent in adult and old $\mathrm{m}$. plantaris of C57BL/ $6 \mathrm{~J}$ mice after 6 weeks overload. The proportional increase in aerobic capacity and muscle fiber size after overload was unexpected as the inverse relationship between fiber size and oxidative capacity (van der Laarse et al. 1998)

old-res control (black) and overloaded (white) muscle in the oxidative and glycolytic muscle regions. $\log _{\mathrm{rSD}}$ was higher in the glycolytic than in the oxidative region of the $m$. plantaris muscle ( $\left.{ }^{\mathrm{g}} P<0.01\right)$, but not affected by age. Overload reduced $\log _{\mathrm{rSD}}$ $\left({ }^{*} P<0.01\right)$, while resveratrol did not affect the $\log _{\mathrm{rSD}}(P>0.05)$. Values are mean \pm SEM. Black bars control situation; white bars overload situation

suggests that oxygen diffusion limitations may impose a size constraint on muscle fibers. The more homogeneous distribution of capillaries in the overloaded muscles improves muscle oxygenation (Degens et al. 1994a; Goldman et al. 2006; Turek et al. 1989) and may make such an adaptation possible in vivo. While resveratrol supplementation did rescue some of the age-related atrophy, it did not affect the fatigue resistance or rescue the angiogenic and hypertrophic response in old age. It is 
Fig. 6 Illustration of the analyses of capillary data. a Typical example of capillaries identified with lectin staining in mice muscle. b In red, the capillaries, and in green, the muscle fiber outlines are shown, while in blue (c), the calculated capillary domains are depicted. $\mathbf{d}$ The overlap of domains and fibers, used to calculate fiber-specific capillary supply, as described in the methods section. Bar represents $30 \mu \mathrm{m}$ (color figure online)

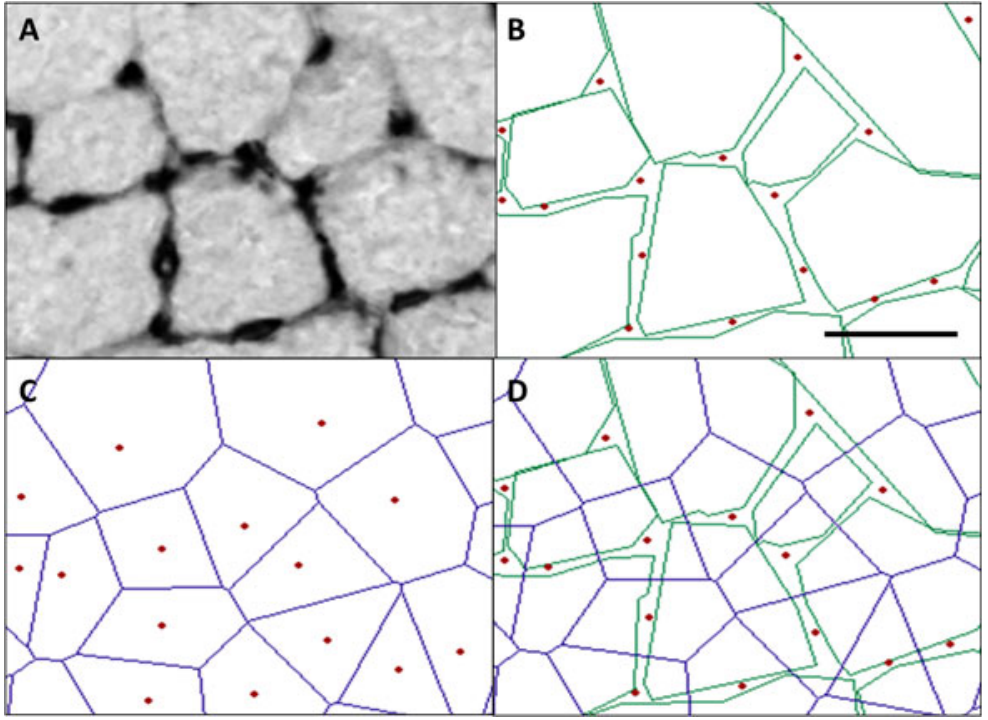

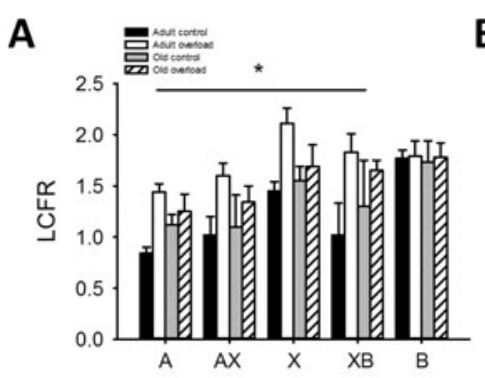

E

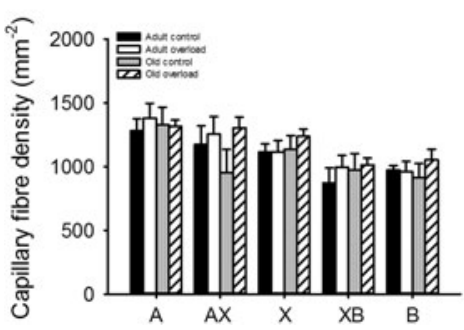

$\mathbf{F}$
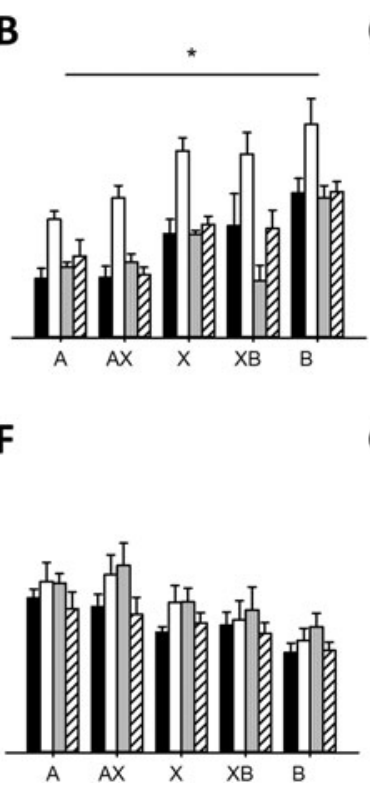

G
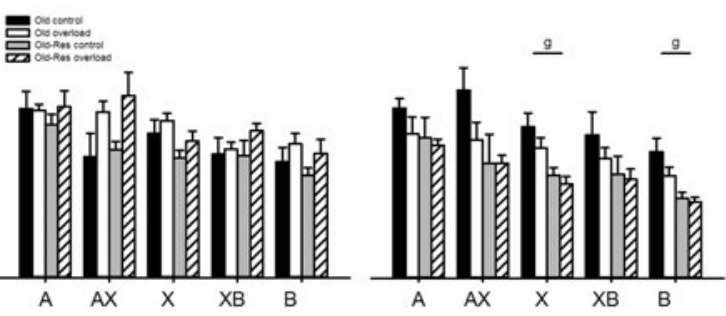

Fig. 7 Effects of age, overload, muscle area and resveratrol supplementation on local capillary to fiber ratio and capillary fiber density. LCFR for adult control (black), overloaded (white), old control (dashed), and overloaded (striped) muscle for type A, X, and $\mathrm{B}$ fibers in the oxidative (a) and glycolytic (b) region of the muscle. LCFR activity for old control (black), overloaded (white), old-res control (dashed) and overloaded (striped) muscle for type $\mathrm{A}, \mathrm{X}$, and B fibers in the oxidative (c) and glycolytic (d) region of the muscle. Overload increased the LCFR in fibers of all types in both regions $(P<0.05)$, except for oxidative type IIB fibers $(P>0.05)$. An interaction effect (age $\times$ overload) showed that the increase in LFCR was larger for adult than for old muscle $(P<0.05)$. Resveratrol did not affect the LCFR $(P>0.05)$. For both old and old-res muscle, the LCFR was higher in the oxidative, compared to the glycolytic part $(P<0.01)$. CFD $\left(\mathrm{mm}^{-2}\right)$ for adult control (black), overloaded (white), old control (dashed), and overloaded (striped) muscle for type A, X, and B fibers in the oxidative (e) and glycolytic (f) region of the muscle. CFD $\left(\mathrm{mm}^{-2}\right)$ for old control (black), overloaded (white), old-res control (dashed) and overloaded (striped) muscle for type A, X and B fibers in the oxidative (g) and glycolytic (h) region of the muscle. CFD showed an age $\times$ overload interaction for type IIAX and IIX fibers, only in the glycolytic region $(P<0.05)$. Resveratrol decreased the CFD for IIAX, X and B fibers in the glycolytic region of the muscle $(P<0.05)$. For type AX fibers, overload increased the CFD in both old and old-res muscle $(P<0.05)$. Furthermore, in IIX and IIB fibers CFD was lower in the glycolytic, compared to the oxidative region (age $\times$ overload interaction; $P<0.05$ ). Data shown are mean \pm SEM 
Fig. 8 SDH activity and FCSA are inversely related. The figure shows the relationship between mean SDH activity per muscle and FCSA for adult and old muscles. Overload affects this relationship by inducing a rightward shift $\left(R^{2}=0.74\right.$; $P<0.01)$, compared to the control $\left(R^{2}=0.67 ; P<0.01\right)$. The black lines represent the best fit hyperbola. Values are mean \pm SEM

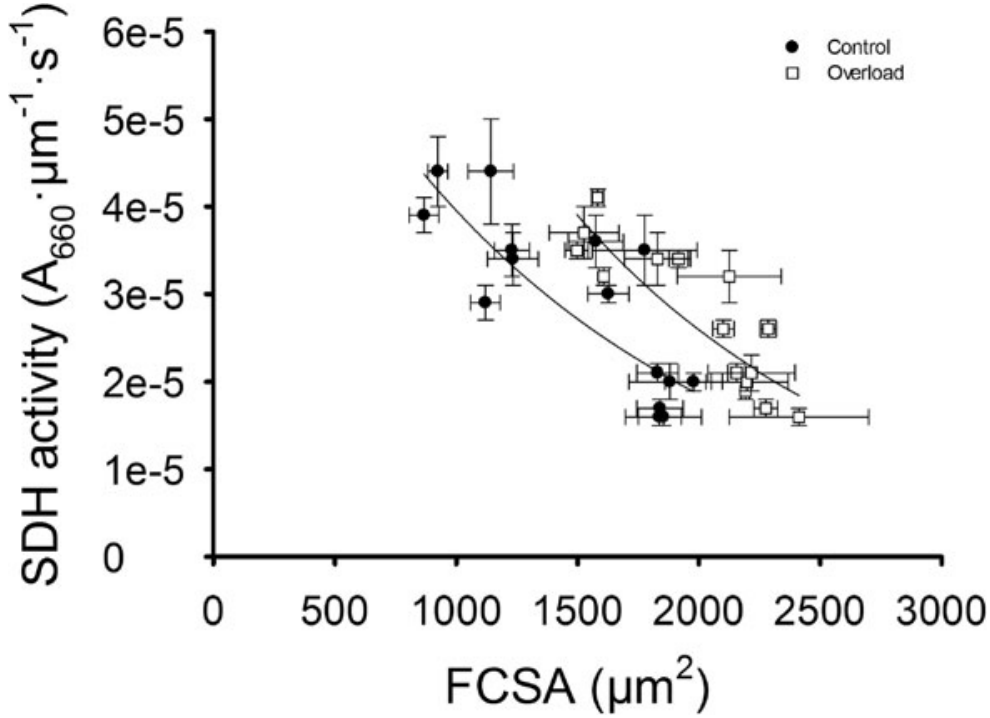

thus possible that impaired angiogenesis contributes to the attenuated hypertrophic response in old age, which cannot be rescued by resveratrol.

Age-related changes in muscle capillarization and oxidative capacity

An adequate capillarization is vital for muscle function, and any impairment in oxygen delivery could have major implications for fatigue resistance. It has been observed in Wistar rats (Degens et al. 1993b) and humans (Proctor et al. 1995) that the capillary supply to fibers is reduced in old age, suggesting an age-related capillary rarefaction. In the present study, both the capillary-to-fiber ratio and the capillary density were similar in adult and old mouse $m$. plantaris, which suggests that in 25-month-old mice, the capillary bed had not yet been significantly affected by age. Nevertheless, we did find a reduced Flk-1 expression in old muscle, similar to a previous study in mice (Wagatsuma 2006), indicative of a reduction in angiogenic signaling in old muscle and possibly an early indication of problems to maintain the vascular bed.

$\mathrm{SDH}$, or complex II, is both part of the citric acid cycle and the respiratory chain. While it has been reported that the SDH activity in the muscle decreases with age (Proctor et al. 1995; Sczelecki et al. 2014), we and others (Doran et al. 2008) found an increased SDH activity in old compared to adult $m$. plantaris. In western blots, however, we observed no age-related change in the expression of SDH, suggesting that the specific activity of the SDH complex was increased. The agerelated increase in SDH activity in our study may be a compensation for the decrease in COX expression, which has also been observed by others (Bua et al. 2006; Lee et al. 1998), in an attempt to maintain aerobic capacity.

The absence of any age-related differences in fatigue resistance during a series of intermittent isometric contractions in our study was similar to that observed in the $m$. plantaris of 13- and 25-month-old Wistar rats (Degens et al. 1993a). This observation was unexpected, considering the age-related increase in the SDH activity and the type IIB to type IIA fiber type transition. Similarly, after overload, the fatigue resistance was increased without a change in SDH activity. The dissociation of changes in fatigue resistance and oxidative capacity suggest that the fatigue test, while useful to distinguish fatigable and fatigue resistant motor units (Larsson et al. 1991) and to predict the aerobic capacity in single muscle fibers, is not as powerful a predictor of aerobic capacity in whole muscle (Degens and Veerkamp 1994). The reason for this may be related to the more severe increase in metabolites during whole muscle fatigue than during single motor unit fatigue development (Gardiner and Olha 1987). If indeed lactate accumulation from glycolytic fibers has a negative impact on the neighboring fatigue-resistant aerobic fibers, one may expect that a higher capillarization will enhance the removal of lactate and be associated with a higher fatigue resistance. Consistent with this, we found that changes in fatigue resistance during aging and 
overload paralleled changes in muscle capillarization. Nevertheless, in rats older than 26 months, there was a significant reduction in fatigue resistance with a similar test (Degens and Alway 2003). This and our previous observations that 25-month-old mice already show agerelated deteriorations in determinants of muscle force generating capacity similar to 60-70-year-old humans (Ballak et al. 2014b) is in line with our suggestion that these mice present a model for early age-related changes in muscle structure and function.

Effects of mechanical overload in old age on muscle morphology and fatigue resistance

Overload increased the FCSA more in adult than in old muscle, confirming the blunted hypertrophic response in old age (Ballak et al. 2015; Degens and Alway 2003). In both adult and old muscle, hypertrophy was accompanied by a proportional increase in the number of capillaries per fiber and fiber size as reflected by the maintained capillary fiber density. However, the increase in LCFR, reflecting the number of capillaries per fiber, was less in old than in adult hypertrophied muscles, indicating impaired angiogenesis. Part of the impaired angiogenic response may be related to the age-related decrease in Flk-1 protein expression, the receptor for VEGF, an important endothelial mitogenic factor (Wagatsuma 2006). An impaired angiogenic response has also been seen in ischemic hind limbs that was due to impaired VEGF expression and HIF-1 $\alpha$ activity in muscles of old animals (Rivard et al. 2000; Rivard et al. 1999). We and others have found a positive relationship between the size of a fiber and the capillary supply in both normal (Ahmed et al. 1997; Wust et al. 2009) and hypertrophied muscle (Degens et al. 1994b) and a similar time course of hypertrophy and angiogenesis (Egginton et al. 2011; Plyley et al. 1998). Whatever the cause, the impaired angiogenesis we observed in the old muscle may thus well contribute, in addition to a reduced Id 2 expression and lower satellite cell number (Ballak et al. 2015), to the blunted hypertrophic response in old age.

The elevated fatigue resistance despite unaltered aerobic capacity in overloaded muscles may be attributable to an increased proportion of slower fibers (type IIB to IIA shift), that are more economical than faster fibers during isometric contractions (Stienen et al. 1996). However, we observed a greater shift to slower fibers in adult than old muscle, while the overload-induced increase in fatigue resistance was similar in adult and old muscle. In theory, an enhanced myoglobin concentration could facilitate the diffusion of oxygen (Kreuzer and Hoofd 1987), but this has been shown to not significantly change during overload (Masuda et al. 1997). Interestingly, the CD was increased and the distribution of capillaries became more homogeneous in both adult and old overloaded muscle, which is expected to improve the oxygenation of the muscle (Degens et al. 2006; Turek et al. 1991) and thereby potentially contribute to the enhanced fatigue resistance in the overloaded muscles. Further support for the potential significance of the distribution of capillaries in muscle fatigue resistance is the absence of a change in both $\mathrm{CD}$ and heterogeneity of capillary spacing on the one hand and fatigue resistance on the other during aging. It is admittedly a tenuous link that needs further investigation.

Effect of resveratrol on muscle morphology and muscle fatigue in old overloaded muscle

Resveratrol is thought to induce its effects via Sirt-1 (Yun et al. 2012) and/or AMP-activated protein kinase activation (Park et al. 2012) that controls PGC- $1 \alpha$ expression (Lagouge et al. 2006). PGC-1 $\alpha$ plays an important role in mitochondrial biogenesis (Goffart and Wiesner 2003) and has been reported to also stimulate angiogenesis (Olesen et al. 2010). Correspondingly, resveratrol supplementation has been shown to improve mitochondrial function, endurance performance and muscle fatigue resistance in rodents (Hart et al. 2013; Lagouge et al. 2006; Murase et al. 2009; Selsby et al. 2012). In contrast to our expectation, resveratrol did not improve capillarization, mitochondrial function, or fatigue resistance. A recent study also did not find any beneficial effects of resveratrol on muscle capillarization in 15-month-old mice (Ringholm et al. 2013) and it has even been shown to limit training-induced angiogenesis in old men (Gliemann et al. 2014). The discrepancy in the published literature and our findings may be related to the dose of resveratrol and the degree of oxidative stress in the muscle (Bosutti and Degens 2015), where we administered $0.4 \%$ resveratrol per gram body mass and others a lower dose $(0.05 \%$ per gram body mass). It is also possible that the beneficial effects of resveratrol on fatigue resistance and the capillary bed only become apparent when muscle capillarization is already impaired.

Relationship between fiber size and aerobic capacity

The inverse relationship between SDH activity and FCSA was suggested to be determined by diffusion 
limitations (Degens 2012). Such an inverse relationship was also observed in our study and did not change during aging. To our surprise, however, the relationship in overloaded muscles was shifted upward, indicating that the maximal oxygen uptake for a fiber with a given FCSA was larger in overloaded than control muscles. It is likely that the improved homogeneity of capillary distribution that improves muscle oxygenation (Degens et al. 1994a; Turek et al. 1991) has made this adaptation possible.

\section{Conclusion}

In conclusion, even though capillarization in muscles from old and adult mice was similar, overload-induced angiogenesis was blunted in old mice. The impaired angiogenic response may at least partly contribute to the blunted hypertrophic response in old age. Despite the attenuated angiogenesis, the fiber hypertrophy and mitochondrial biogenesis in response to overload were all proportional, so that the relationships between fiber capillarization, aerobic capacity, and size were similar in control and overloaded muscle of both adult and old mice.

The increased total oxidative capacity of a fiber of a given size and the increased fatigue resistance of overloaded muscles may be partly attributable to an increased capillary density and a more homogeneous distribution of capillaries. Resveratrol supplementation attenuated age-related muscle wasting, but did not improve fatigue resistance or capillarization.

Acknowledgments This research was funded by the European Commission through MOVE-AGE, an Erasmus Mundus Joint Doctorate program (2011-0015). The authors are grateful for 21st Century Alternative, UK, for providing the resveratrol for this study. The authors would also like to acknowledge Sreeda Chalil, Eva Peters, Evelien Bos, Frank van 't Hoff, and Joshua Dunnink for their support in the western blot and histological measurements.

Compliance with ethical standards All experiments were approved by the local animal use and care committee of the VU University Amsterdam and conformed to the Dutch Research Council's guide for care and use of laboratory animals.

Conflict of interest The authors declare that they have no conflicts of interest. The sponsor was in no way involved in the design or execution of this study.

Open Access This article is distributed under the terms of the Creative Commons Attribution 4.0 International License (http:// creativecommons.org/licenses/by/4.0/), which permits unrestricted use, distribution, and reproduction in any medium, provided you give appropriate credit to the original author(s) and the source, provide a link to the Creative Commons license, and indicate if changes were made.

\section{References}

Ahmed SK, Egginton S, Jakeman PM, Mannion AF, Ross HF (1997) Is human skeletal muscle capillary supply modelled according to fibre size or fibre type? Exp Physiol 82:231-234

Al-Shammari AA, Gaffney EA, Egginton S (2014) Modelling capillary oxygen supply capacity in mixed muscles: Capillary domains revisited. J Theor Biol 356c:47-61. doi: 10.1016/j.jtbi.2014.04.016

Ballak SB, Degens H, Busé-Pot T, de Haan A, Jaspers RT (2014a) Plantaris muscle weakness in old mice: relative contributions of changes in specific force, muscle mass, myofiber crosssectional area, and number. Age 36:1-11

Ballak SB, Degens H, de Haan A, Jaspers RT (2014b) Aging related changes in determinants of muscle force generating capacity: a comparison of muscle aging in men and male rodents. Ageing Res Rev 14:43-55. doi:10.1016/j.arr.2014. 01.005

Ballak SB, Jaspers RT, Deldicque L, Chalil S, Peters EL, de Haan A, Degens H (2015) Blunted hypertrophic response in old mouse muscle is associated with a lower satellite cell density and is not alleviated by resveratrol. Exp Gerontol. doi:10. 1016/j.exger.2014.12.020

Ballak SB, Yap MH, Harding PJ, Degens H (2016) Validation of a new semi-automated technique to evaluate muscle capillarization. Adv Exp Med Biol 876:87-93. doi:10.1007/ 978-1-4939-3023-4_11

Bosutti A, Degens H (2015) The impact of resveratrol and hydrogen peroxide on muscle cell plasticity shows a dosedependent interaction. Sci Rep 5:8093. doi:10.1038/ srep08093

Bua E, Johnson J, Herbst A, Delong B, McKenzie D, Salamat S, Aiken JM (2006) Mitochondrial DNA-deletion mutations accumulate intracellularly to detrimental levels in aged human skeletal muscle fibers. Am J Hum Genet 79:469-480. doi:10.1086/507132

Coggan AR, Spina RJ, King DS, Rogers MA, Brown M, Nemeth PM, Holloszy JO (1992) Histochemical and enzymatic comparison of the gastrocnemius muscle of young and elderly men and women. J Gerontol 47:B71-B76

de Haan A, Jones DA, Sargeant AJ (1989) Changes in velocity of shortening, power output and relaxation rate during fatigue of rat medial gastrocnemius muscle. Pflugers Arch - Eur J Physiol 413:422-428

Degens H (1998) Age-related changes in the microcirculation of skeletal muscle. Adv Exp Med Biol 454:343-348

Degens H (2012) Determinants of skeletal muscle hypertrophy and the attenuated hypertrophic response at old age. Sports Med Doping Stud S1:1-8 
Degens H, Alway SE (2003) Skeletal muscle function and hypertrophy are diminished in old age. Muscle Nerve 27:339-347. doi:10.1002/mus. 10314

Degens H, Veerkamp JH (1994) Changes in oxidative capacity and fatigue resistance in skeletal muscle. Int J Biochem 26:871878

Degens H, Turek Z, Hoofd LJ, Van't Hof MA, Binkhorst RA (1992) The relationship between capillarisation and fibre types during compensatory hypertrophy of the plantaris muscle in the rat. J Anat 180(Pt 3):455-463

Degens H, Turek Z, Binkhorst RA (1993a) Compensatory hypertrophy and training effects on the functioning of aging rat $M$. plantaris. Mech Ageing Dev 66:299-311

Degens H, Turek Z, Hoofd L, van't Hof MA, Binkhorst RA (1993b) Capillarisation and fibre types in hypertrophied $M$. plantaris in rats of various ages. Respir Physiol 94:217-226

Degens H, Ringnalda BE, Hoofd LJ (1994a) Capillarisation, fibre types and myoglobin content of the dog gracilis muscle. Adv Exp Med Biol 361:533-539

Degens H, Turek Z, Hoofd LJC, Binkhorst RA (1994b) Capillary proliferation related to fibre types in hypertrophied ageing rat m. plantaris. Adv Exp Med Biol 345:669-676

Degens H, Deveci D, Botto-van Bemden A, Hoofd LJ, Egginton S (2006) Maintenance of heterogeneity of capillary spacing is essential for adequate oxygenation in the soleus muscle of the growing rat. Microcirculation 13:467-476. doi:10.1080/ 10739680600776286

Doran P, O'Connell K, Gannon J, Kavanagh M, Ohlendieck K (2008) Opposite pathobiochemical fate of pyruvate kinase and adenylate kinase in aged rat skeletal muscle as revealed by proteomic DIGE analysis. Proteomics 8:364-377. doi:10. 1002/pmic.200700475

Egginton S, Badr I, Williams J, Hauton D, Baan GC, Jaspers RT (2011) Physiological angiogenesis is a graded, not threshold, response. J Physiol 589:195-206. doi:10.1113/jphysiol.2010. 194951

Fleg JL, Lakatta EG (1988) Role of muscle loss in the ageassociated reduction in VO2 max. J Appl Physiol 65:11471151

Fleg JL, Morrell CH, Bos AG, Brant LJ, Talbot LA, Wright JG, Lakatta EG (2005) Accelerated longitudinal decline of aerobic capacity in healthy older adults. Circulation 112:674 682. doi:10.1161/circulationaha.105.545459

Fukuda S, Kaga S, Zhan L, Bagchi D, Das DK, Bertelli A, Maulik N (2006) Resveratrol ameliorates myocardial damage by inducing vascular endothelial growth factor-angiogenesis and tyrosine kinase receptor Flk-1. Cell Biochem Biophys 44:43-49. doi:10.1385/cbb:44:1:043

Gardiner PF, Olha AE (1987) Contractile and electromyographic characteristics of rat plantaris motor unit types during fatigue in situ. J Physiol 385:13-34

Gliemann L et al. (2014) Resveratrol modulates the angiogenic response to exercise training in skeletal muscle of aged men. Am J Physiol Heart Circ Physiol. doi:10.1152/ajpheart. 00168.2014

Goffart S, Wiesner RJ (2003) Regulation and co-ordination of nuclear gene expression during mitochondrial biogenesis. Exp Physiol 88:33-40

Goldman D, Bateman RM, Ellis CG (2006) Effect of decreased $\mathrm{O} 2$ supply on skeletal muscle oxygenation and $\mathrm{O} 2$ consumption during sepsis: role of heterogeneous capillary spacing and blood flow. Am J Physiol Heart Circ Physiol 290: H2277-H2285. doi:10.1152/ajpheart.00547.2005

Hart $\mathrm{N}$ et al. (2013) Resveratrol enhances exercise training responses in rats selectively bred for high running performance. Food Chem Toxicol 61:53-59. doi:10.1016/j.fct.2013.01. 051

Hepple RT, Vogell JE (2004) Anatomic capillarization is maintained in relative excess of fiber oxidative capacity in some skeletal muscles of late middle-aged rats. J Appl Physiol 96: 2257-2264. doi:10.1152/japplphysiol.01309.2003

Hepple RT, Mackinnon SL, Goodman JM, Thomas SG, Plyley MJ (1997) Resistance and aerobic training in older men: effects on VO2peak and the capillary supply to skeletal muscle. J Appl Physiol 82:1305-1310

Hepple RT, Hagen JL, Krause DJ, Jackson CC (2003) Aerobic power declines with aging in rat skeletal muscles perfused at matched convective O2 delivery. J Appl Physiol 94:744-751. doi:10.1152/japplphysiol.00737.2002

Hoofd L, Turek Z, Kubat K, Ringnalda BE, Kazda S (1985) Variability of intercapillary distance estimated on histological sections of rat heart. Adv Exp Med Biol 191:239-247

Hudlicka O, Brown M, Cotter M, Smith M, Vrbova G (1977) The effect of long-term stimulation of fast muscles on their blood flow, metabolism and ability to withstand fatigue. Pflugers Arch - Eur J Physiol 369:141-149

Jackson JR, Ryan MJ, Alway SE (2011) Long-term supplementation with resveratrol alleviates oxidative stress but does not attenuate sarcopenia in aged mice. The journals of gerontology Series A, Biol Sci Med Sci 66:751-764. doi:10.1093/ gerona/glr047

Konopka AR, Suer MK, Wolff CA, Harber MP (2014) Markers of human skeletal muscle mitochondrial biogenesis and quality control: effects of age and aerobic exercise training. J Gerontol A Biol Sci Med Sci 69:371-378. doi:10.1093/ gerona/glt107

Kosek DJ, Kim JS, Petrella JK, Cross JM, Bamman MM (2006) Efficacy of 3 days/wk resistance training on myofiber hypertrophy and myogenic mechanisms in young vs. older adults. $\mathrm{J}$ Appl Physiol 101:531-544. doi:10.1152/japplphysiol.01474. 2005

Kreuzer F, Hoofd L (1987) Facilitated diffusion of oxygen and carbon dioxide. In: Handbook of Physiology, vol Vol. IV, The respiratory system: Gas exchange. Am Physiol Soc, pp 89111

Lagouge $\mathrm{M}$ et al. (2006) Resveratrol improves mitochondrial function and protects against metabolic disease by activating SIRT1 and PGC-1alpha. Cell 127:1109-1122. doi:10.1016/j. cell.2006.11.013

Larsson L, Ansved T, Edstrom L, Gorza L, Schiaffino S (1991) Effects of age on physiological, immunohistochemical and biochemical properties of fast-twitch single motor units in the rat. J Physiol 443:257-275

Lee CM, Lopez ME, Weindruch R, Aiken JM (1998) Association of age-related mitochondrial abnormalities with skeletal muscle fiber atrophy. Free Radic Biol Med 25:964-972

Leick L, Hellsten Y, Fentz J, Lyngby SS, Wojtaszewski JF, Hidalgo J, Pilegaard H (2009) PGC-1alpha mediates exercise-induced skeletal muscle VEGF expression in mice American journal of physiology. Endocrinol Metab 297: E92-103. doi:10.1152/ajpendo.00076.2009 
Maden-Wilkinson TM, McPhee JS, Jones DA, Degens H (2015) Age related loss of muscle mass, strength and power and their association with mobility in recreationally active UK older adults. J Aging Phys Act. doi:10.1123/japa.2013-0219

Masuda K, Kano Y, Katsuta S (1997) Adaptation of myoglobin in compensatory hypertrophied rat muscle. Acta Physiol Scand 160:327-331. doi:10.1046/j.1365-201X.1997.00170.x

Murase T, Haramizu S, Ota N, Hase T (2009) Suppression of the aging-associated decline in physical performance by a combination of resveratrol intake and habitual exercise in senescence-accelerated mice. Biogerontology 10:423-434. doi:10.1007/s10522-008-9177-z

Olesen J, Kiilerich K, Pilegaard H (2010) PGC-1alpha-mediated adaptations in skeletal muscle. Pflugers Arch 460:153-162. doi:10.1007/s00424-010-0834-0

Park SJ et al. (2012) Resveratrol ameliorates aging-related metabolic phenotypes by inhibiting cAMP phosphodiesterases. Cell 148:421-433. doi:10.1016/j.cell.2012.01.017

Paterson DH, Jones GR, Rice CL (2007) Ageing and physical activity: evidence to develop exercise recommendations for older adults. Can J Public Health $=$ Revue Canadienne de Sante Publique 98(Suppl 2):S69-108

Plyley MJ, Olmstead BJ, Noble EG (1998) Time course of changes in capillarization in hypertrophied rat plantaris muscle. $\mathrm{J}$ Appl Physiol 84:902-907

Proctor DN, Sinning WE, Walro JM, Sieck GC, Lemon PW (1995) Oxidative capacity of human muscle fiber types: effects of age and training status. J Appl Physiol 78:20332038

Ringholm S et al. (2013) Effect of lifelong resveratrol supplementation and exercise training on skeletal muscle oxidative capacity in aging mice; impact of PGC-1alpha. Exp Gerontol 48:1311-1318. doi:10.1016/j.exger.2013.08.012

Rivard A et al. (1999) Age-dependent impairment of angiogenesis. Circulation 99:111-120

Rivard A et al. (2000) Age-dependent defect in vascular endothelial growth factor expression is associated with reduced hypoxia-inducible factor 1 activity. J Biophys Chem 275: 29643-29647. doi:10.1074/jbc.M001029200

Roseberg IH (1989) Summary comments. Am J Clin Nutr 50: $1231-1233$

Ryan MJ, Jackson JR, Hao Y, Williamson CL, Dabkowski ER, Hollander JM, Alway SE (2010) Suppression of oxidative stress by resveratrol after isometric contractions in gastrocnemius muscles of aged mice. The journals of gerontology Series A, Biol Sci Med Sci 65:815-831. doi:10.1093/gerona/ glq080

Sczelecki S et al. (2014) Loss of Pgc-1alpha expression in aging mouse muscle potentiates glucose intolerance and systemic inflammation American journal of physiology. Endocrinol Metab 306:E157-E167. doi:10.1152/ajpendo.00578.2013

Selsby JT, Morine KJ, Pendrak K, Barton ER, Sweeney HL (2012) Rescue of dystrophic skeletal muscle by PGC-1alpha involves a fast to slow fiber type shift in the $\mathrm{mdx}$ mouse. PLoS One 7:e30063. doi:10.1371/journal.pone.0030063

Skorjanc D, Dunstl G, Pette D (2001) Mitochondrial enzyme defects in normal and low-frequency-stimulated muscles of young and aging rats. The journals of gerontology Series A, Biol Sci Med Sci 56:B503-B509

Stienen GJ, Kiers JL, Bottinelli R, Reggiani C (1996) Myofibrillar ATPase activity in skinned human skeletal muscle fibres: fibre type and temperature dependence. J Physiol 493(Pt 2): 299-307

Suzuki J, Gao M, Batra S, Koyama T (1997) Effects of treadmill training on the arteriolar and venular portions of capillary in soleus muscle of young and middle-aged rats. Acta Physiol Scand 159:113-121. doi:10.1046/j.1365-201X.1997. 582353000.x

Turek Z, Olders J, Hoofd L, Egginton S, Kreuzer F, Rakusan K (1989) PO2 histograms in various models of tissue oxygenation in skeletal muscle. Adv Exp Med Biol 248:227-237

Turek Z, Rakusan K, Olders J, Hoofd L, Kreuzer F (1991) Computed myocardial PO2 histograms: effects of various geometrical and functional conditions. J Appl Physiol 70: $1845-1853$

van der Laarse WJ, Diegenbach PC, Elzinga G (1989) Maximum rate of oxygen consumption and quantitative histochemistry of succinate dehydrogenase in single muscle fibres of Xenopus laevis. J Muscle Res Cell Motil 10:221-228

van der Laarse WJ, Des Tombe AL, Lee-De Groot MBE, Diegenbach PC (1998) Size principle of striated muscle cells. Neth J Zool 48(3):213-223

van der Laarse WJ, des Tombe AL, van Beek-Harmsen BJ, Lee-de Groot MB, Jaspers RT (2005) Krogh's diffusion coefficient for oxygen in isolated Xenopus skeletal muscle fibers and rat myocardial trabeculae at maximum rates of oxygen consumption. J Appl Physiol 99:2173-2180. doi:10.1152/ japplphysiol.00470.2005

van Wessel T, de Haan A, van der Laarse WJ, Jaspers RT (2010) The muscle fiber type-fiber size paradox: hypertrophy or oxidative metabolism? Eur J Appl Physiol 110:665-694. doi:10.1007/s00421-010-1545-0

Wagatsuma A (2006) Effect of aging on expression of angiogenesis-related factors in mouse skeletal muscle. Exp Gerontol 41:49-54. doi:10.1016/j.exger.2005.10.003

Welle S, Totterman S, Thornton C (1996) Effect of age on muscle hypertrophy induced by resistance training. J Gerontol A Biol Sci Med Sci 51:M270-M275

Wust RC, Gibbings SL, Degens H (2009) Fiber capillary supply related to fiber size and oxidative capacity in human and rat skeletal muscle. Adv Exp Med Biol 645:75-80. doi:10.1007/ 978-0-387-85998-9 12

Yun JM, Chien A, Jialal I, Devaraj S (2012) Resveratrol upregulates SIRT1 and inhibits cellular oxidative stress in the diabetic milieu: mechanistic insights. J Nutr Biochem 23: 699-705. doi:10.1016/j.jnutbio.2011.03.012 